\title{
Técnica de análise cefalométrica de tecidos moles: uma revisão de literatura
}

\author{
Technique of soft tissues cefalometric analysis: a literature review \\ Técnica de análisis cefalométrico de tejidos blandos: \\ una revisión de literatura \\ Marina Tavares Costa NÓBREGA ${ }^{1}$ \\ Julliana Cariry Palhano FREIRE ${ }^{1}$ \\ Ohana Rodrigues FARIAS ${ }^{2}$ \\ Stéphanie Cariry Palhano FREIRE ${ }^{3}$ \\ Eduardo SANT'ANA ${ }^{4}$ \\ Eduardo DIAS-RIBEIRO 5 \\ ${ }^{I}$ Doutoranda em Clínica Odontológica pela Universidade Estadual da Paraíba, Campina Grande, Paraíba, Brasil \\ ${ }^{2}$ Doutoranda em Clínica Odontológica pela Universidade Estadual da Paraíba, \\ Professora de Odontologia da Universidade Federal de Campina Grande, Patos, Paraíba, Brasil \\ ${ }^{2}$ Mestre em Ciências Odontológicas pela Universidade Federal da Paraíba, João Pessoa, Paraíba, Brasil \\ ${ }^{3}$ Enfermeira. Hospital Universitário Alcides Carneiro, Campina Grande, Paraíba Brasil \\ ${ }^{4}$ Professor associado da Faculdade de Odontologia de Bauru, Universidade de São Paulo (FOB-USP), Bauru, São Paulo, Brasil \\ ${ }^{5}$ Professor adjunto da Universidade Federal de Campina Grande, Patos, Paraíba, Brasil
}

\begin{abstract}
Resumo
Introdução: Por muito tempo as análises cefalométricas se restringiam aos tecidos duros, porém de algumas décadas pra cá, foi visto que a harmonia entre os tecidos é fundamental para um perfil facial agradável. Objetivo: O presente estudo teve como objetivo realizar uma revisão de literatura acerca do uso da análise cefalométrica de tecidos moles (ACTM). Metodologia: Foram analisados artigos científicos obtidos da base de dados PubMed, do período de 2000 à 2016, de acordo com os descritores: Norm (s), Soft tissue (s), Arnett, Cephalometry, bem como a associação dos termos. Totalizando-se 18 estudos, que utilizavam a análise cefalométrica de tecidos moles de Arnett al. (1999), para pacientes sem deformidades faciais. Os dados foram analisados a partir de estatística descritiva. Resultados: O continente asiático se destaca na quantidade de estudos envolvendo essa técnica, com 12 trabalhos, seguido pelo continente americano, com 4, enquanto na Oceania não foi encontrado nenhum estudo seguindo os critérios de inclusão. Conclusão: Concluiu-se através dos estudos encontrados, que a técnica de análise cefalométrica dos tecidos moles é conhecida e utilizada pelas diversas partes do mundo. E também que a individualidade do paciente deve ser levada em conta para o planejamento do tratamento, pois fatores como gênero e etnia influenciam em suas características faciais.
\end{abstract}

Descritores: Cefalometria; Estética; Face.

\section{Abstract}

Introduction: For a long time cephalometric analyzes were restricted to hard tissues, but from a few decades to now, it was seen that the harmony between tissues is fundamental for a pleasant facial profile. Objective: The objective of this study was to perform a literature review on the use of cephalometric soft tissue analysis (ACTM), proposed by Arnett et al. (1999). Methodology: Scientific articles were obtained from the PubMed database, from 2000 to 2016, according to the descriptors: Norm (s), Soft tissue (s), Arnett, Cephalometry, as well as the association of terms. A total of 18 studies using the cephalometric soft tissue analysis of Arnett al. (1999), for patients without facial deformities. Data were analyzed using descriptive statistics. Results: The Asian continent stands out in the number of studies involving this technique, with 12 studies, followed by the American continent, with 4, whereas in Oceania no study was found following our inclusion criteria. Conclusion: It was concluded through the studies found that the technique of cephalometric analysis of the soft tissues known and used by different parts of the world. Also, the individuality of the patient should be taken into account for treatment planning, since factors such as gender and ethnicity influence their facial characteristics.

Descriptors: Cephalometry; Esthetics; Face.

\section{Resumen}

Introducción: Por mucho tiempo los análisis cefalométricos se restringían a los tejidos duros, pero de algunas décadas para acá, fue visto que la armonía entre los tejidos es fundamental para un perfil facial agradable. Objetivo: El presente estudio tuvo como objetivo realizar una revisión de literatura acerca del uso del análisis cefalométrico de tejidos blandos (ACTM). Metodología: Se analizaron artículos científicos obtenidos de la base de datos PubMed, del período 2000 al 2016, de acuerdo con los descriptores: Norm (s), Soft tissue (s), Arnett, Cephalometry, así como la asociación de los términos. Totalizándose 18 estudios, que utilizaban el análisis cefalométrico de tejidos blandos de Arnett al. (1999), para pacientes sin deformidades faciales. Los datos fueron analizados a partir de estadística descriptiva. Resultados: El continente asiático se destaca en la cantidad de estudios involucrando esa técnica, con 12 trabajos, seguido por el continente americano, con 4, mientras que en Oceanía no se encontró ningún estudio siguiendo los criterios de inclusión. Conclusión: Se concluyó a través de los estudios encontrados, que la técnica de análisis cefalométrico de los tejidos blandos es conocida y utilizada por las diversas partes del mundo. Y también que la individualidad del paciente debe ser tenida en cuenta para la planificación del tratamiento, pues factores como género y etnia influencian en sus características faciales.

Descriptores: Cefalometría; Estética; Cara.

\section{INTRODUÇÃO}

A estética representa a individualidade do ser humano e é influenciada pelo ambiente e pela sensibilidade de quem olha. ${ }^{1}$ A beleza demonstra a subjetividade a qual por definição é representada pela harmonia e pelo equilíbrio. Na face, as estruturas esqueléticas, os dentes e o tecido mole que os recobre, são os responsáveis pela beleza. ${ }^{2}$

Angle foi um dos primeiros a propor padrões de beleza em Ortodontia. ${ }^{3} \mathrm{O}$ brasileiro é um exemplo de miscigenação, haja visto a sua história de colonização e a heterogenicidade nos padrões faciais. Definir os critérios de beleza para o brasileiro baseado em um único padrão representa uma tarefa difícil. ${ }^{4}$

Desde a sua introdução por Broadbent ${ }^{5}$ em 1931 a radiografia cefalométrica tornou-se uma das ferramentas mais importantes na clínica e pesquisa odontológica. A partir deste momento, foram determinados diferentes pontos de referência que permitiam obter medidas angulares e lineares, no intuito de gerar padrões cefalométricos médios.

A análise cefalometrica caracterizou-se, muitas vezes, como uma ferramenta indispensável para o plano de tratamento e monitoramento tanto dos procedimentos 
cirúrgicos, quanto das mudanças no crescimento em pacientes com deformidades dentofaciais. ${ }^{1}$

Por muitos anos, os trabalhos cefalométricos discorriam principalmente as alterações esqueléticas, decorrentes do tratamento ortodôntico, e pouco se enfatizava as alterações do tecido mole. ${ }^{6}$

Arnett e Bergman ${ }^{7,8}$ apresentaram um artigo dividido em duas partes, com o título: "Chaves faciais para o diagnóstico ortodôntico e plano de tratamento". Os autores apresentam 19 chaves faciais para funcionarem como ferramentas auxiliares, com o objetivo de aprimorar os resultados facial e dentário. Tomando como base os estudos anteriores, Arnett et al. ${ }^{9}$ desenvolveram em 1999 a análise cefalométrica dos tecidos moles (ACTM) que tem por objetivo avaliar durante o planejamento ortodônticocirúrgico, o posicionamento ideal dos dentes e das bases ósseas, prevendo um resultado harmonioso para o tecido tegumentar que os recobre.

Diante desse contexto, o presente estudo teve como objetivo realizar uma revisão de literatura acerca do uso da análise cefalométrica de tecidos moles (ACTM), proposta por Arnett et al. ${ }^{9}$.

\section{MATERIAL E MÉTODO}

Realizou-se uma revisão bibliográfica, onde foram analisados artigos científicos obtidos da base de dados PubMed. Foram incluídos os estudos do período de 2000 à 2016, de acordo com os descritores: Norm (s), Soft tissue (s), Arnett, Cephalometry, bem como a associação dos termos e artigos que utilizavam a análise cefalométrica de tecidos moles de Arnett al. ${ }^{9}$ para pacientes sem deformidades faciais, totalizando-se 18 estudos. As pesquisas que não se enquadraram a esses critérios foram excluídas. Os dados foram analisados a partir de estatística descritiva.

\section{REVISÃO DE LITERATURA E DISCUSSÃO}

Estudos mostram que a individualidade do paciente deve ser levada em consideração para o planejamento do tratamento, pois fatores como gênero e etnia influenciam em suas características faciais.

No trabalho desenvolvido por Anic-Milosevic et al. ${ }^{10}$ isso é afirmado, através dos resultados que mostram que mesmo duas populações de caucasianos, sendo croatas e norte-americanos, apresentam diferenças nas análises de perfil mole. Já Fadeju et al. ${ }^{11}$ concluem que os indivíduos oriundos de Ghana, Nigéria e Senegal apresentam algumas diferenças, porém no geral têm perfis faciais semelhantes entre si, divergindo quando comparados as normas propostas para caucasianos.

Avaliando os estudos publicados que utilizaram a ACTM proposta por Arnett et al. ${ }^{9}$, Alcalde et al. ${ }^{12}$ conduziram pesquisa para estabelecer as normas cefalométricas para o tecido mole em japoneses. $\mathrm{O}$ critério de seleção de um grupo foi a presença de relação dentária normal, sem fazer menção à estética, e o outro grupo, denominado supernormal, foi selecionado por dez examinadores com referência à estética facial. Os autores compararam esses valores com um terceiro grupo formado por indivíduos leucodermas. Os resultados demonstraram que os valores do tecido mole do grupo supernormal diferiram menos dos índices normativos para leucodermas do que da amostra com oclusão normal.

Hwang et al. ${ }^{13}$ compararam pacientes adultos coreanos com europeus e americanos, e perceberam que a amostra coreana mostrou um menor ângulo de inclinação nasal e uma maior protrusão labial em comparação com a amostra européia-americana. A protrusão mentual dos coreanos era menos evidente do que a dos europeus e americanos.

Al-Gunaid et al. $^{16}$ (2007) estudaram comparativamente uma amostra de árabes com leucodermas norte-americanos. Encontraram maior prognatismo mandibular, menores ângulos das da linha queixo-pescoço e nasolabial, e sulco mentolabial mais profundo quando comparado com leucodermas norte-americanos.

Uysal et al. ${ }^{17}$ (2009) avaliaram comparativamente indivíduos turcos com os valores de referência do leucoderma norte-americano. Encontraram que a espessura do lábio inferior foi menor e que a espessura do mento foi maior do que os resultados encontrados nos norteamericanos. Os indivíduos turcos apresentam rima infraorbital, maçã do rosto e subpupila deprimidos, lábios superiores e inferiores retos e finos, além de incisivos, pogônio e ponto $B$ retruídos.

Gu et al. ${ }^{18}$ (2011), em seu estudo cujo objetivo foi de comparar o perfil de chineses e caucasianos, encontram diferenças em tecidos mole, como também em tecidos duros desses pacientes. O que nos mostra que essas diferenças devem ser considerados na formulação de um plano de tratamento ortodôntico para pacientes de diferentes origens étnicas.

As diferenças existentes no perfil facial entre gêneros é evidenciada em estudos como o de Shindoi et al. ${ }^{19}$ (2013), no qual foram analisadas radiografias cefalométricas de japoneses do sexo femino e masculino. Como resultados, a equipe encontrou que homens apresentam ângulo nasolabial mais agudo que as mulheres, mostram maiores valores para espessura de lábio superior e menores valores para lábio inferior, além de tecido mais espesso na região do mento. Mulheres têm um terço médio mais projetado do que homens. Concluindo que existem diferenças estatisticamente significantes entre homens e mulheres.

O trabalho de El Hayeck et al. ${ }^{20}$ (2016), também avaliou as diferenças entre os perfis de homens e mulheres, porém no Líbano, e concluíram que as principais diferenças entre os gêneros se referiam a uma maior altura facial inferior e uma lábio inferior mais espesso na população masculina, que também apresentou um lábio superior mais retruídoe um ápice nasal mais protruído. Enquanto a feminina, apresentou ângulos mentolabiais e frontonasais maiores.

No estudo desenvolvido por Sinojyia et al. ${ }^{21}$ (2014), o objetivo foi estabelecer normas cefalométricas para as relações esqueléticas e dentárias, e tecidos moles, entre a população adulta de Mahabubnagar, na Índia. Os valores obtidos a partir do estudo mostraram diferença significativa na maior parte dos parâmetros quando comparados com normas de Arnett et al. ${ }^{9}$ (1999) entre homens e mulheres. Os homens tinham tecido mole mais espesso, ângulo nasolabial agudo, aumento do comprimento facial, aumento da deficiência de terço médio da face, perfil mais convexo e incisivos inferiores menos verticalizados do que as mulheres.

Os achados de Kalha et al. ${ }^{22}$ (2008) nos mostram que na população do sul da Índia, assim como em outros estudos previamente citados, os homens apresentaram estruturas de tecido mole mais espessas e um ângulo nasolabial mais agudo. Possuíam também, a face mais alongada, e as mulheres demonstravam uma boa exposição de incisivo superior. Pessoas do sul da Índia apresentavam maior protrusão dentária do que as normas estabelecidas para 
pessoas brancas.

Biradar; Madanagowda ${ }^{23}$ realizaram um estudo para estabelecer normas de tecido mole utilizando ângulos de perfil e análise estética na população do sul da Índia, e encontraram que não havia nenhuma diferença estatisticamente significativa entre homens e mulheres, exceto para a posição dos incisivos superiores.

A análise cefalométrica dos tecidos moles desenvolvida por Arnett et al. ${ }^{9}$ foi usada no trabalho de Prabu et al. $^{24}$ para estabelecer os parâmetros de lábio e queixo normais para a população do sul da Índia. Foi encontrado que os tecidos dos lábios, tanto superior quanto inferior, e da região do mento, se mostraram mais finos do que os registrados por Arnett et al. ${ }^{9}$. Constatou-se, também, que a distância interlabial foi maior entre as mulheres do que entre os homens.

Singh et al. ${ }^{25}$ também desenvolveram um estudo com uma população da Índia, e compararam os resultados entre os gêneros e com os parâmetros previamente existentes para brancos. Dentre as conclusões feitas podemos observar que: os incisivos superiores são mais vestibularizados e incisivos inferiores são verticalizados em homens indianos, em comparação com caucasianos do sexo masculino, enquanto que os incisivos inferiores são mais protruídos nas mulheres da Índia, em comparação com as mulheres caucasianas; todos os tecidos moles dos indianos se apresentaram mais espessos do que os caucasianos; o ângulo nasolabial é agudo em indianos e é obtuso em indianas, em comparação com população caucasiana; o comprimento facial total é menor em homens e mulheres da Índia, quando comparados com a população caucasiana; há uma deficiência de terço médio da face em ambos os gêneros da população indiana; possuem perfil mais convexo e apresentam o queixo mais retrognata, em comparação com a população caucasiana.

$\mathrm{O}$ estudo de Dias-Ribeiro et al. ${ }^{4}$ analisou o perfil facial de mulheres do Nordeste brasileiro, brancas, com idade entre 18 e 30 anos, pais nordestinos, com oclusão normal e que nunca tivessem sido submetidas a tratamento ortodôntico e comparou com o grupo estudados por Sant'Ana et al. ${ }^{26}$, que analisaram comparativamente o perfil de normalidade dos brasileiros leucodermas do Sudeste do Brasil com os leucodermas norte-americanos. Sant'Ana et $\mathrm{al}^{26}$ encontraram que o perfil do brasileiro é quase totalmente diferente do perfil norte-americano. Os brasileiros apresentam uma face menos protruída, um perfil mais convexo e menor proeminência do queixo. DiasRibeiro et al. ${ }^{4}$ observaram que o plano oclusal das nordestinas se mostrou mais inclinado, maior sobremordida e lábio inferior mais espesso, além de uma menor projeção nasal, menor projeção do terço médio e inferior da face e um ângulo nasolabial mais obtuso, com consequente menor inclinação dos incisivos superiores do que as do Sudeste brasileiro. O perfil das mulheres do Nordeste do Brasil apresentaram um perfil mais retrognata.

Por meio dos estudos encontrados, torna-se notório que a técnica de análise cefalométrica dos tecidos moles proposta por Arnett et al. ${ }^{9}$ é conhecida e utilizada pelas diversas partes do mundo. $\mathrm{O}$ que pode ser confirmado na Tabela 1.

No Gráfico 1 a distribuição desses estudos pelos continentes fica mais perceptível. Pode-se perceber que o continente asiático se destaca na quantidade de estudos envolvendo essa técnica, com 12 trabalhos, seguido pelo continente americano, com 4, enquanto na Oceania não foi encontrado nenhum estudo seguindo nossos critérios de inclusão. O trabalho realizado na Turquia foi incluído na
Europa e também na Ásia, já que se trata de um país euroasiático.

Verificou-se pelos artigos científicos que pessoas de uma mesma raça e região, divergem significativamente quanto a características faciais, se pertencerem a gêneros distintos. A localidade geográfica também influcencia nos padrões faciais, havendo diferenças em indivíduos que pertencem ao mesmo lugar.

Tabela1. Distribuição geográfica dos estudos sobre a técnica de análise cefalométrica dos tecidos moles proposta por Arnett et al ${ }^{9}$

\begin{tabular}{|c|c|c|}
\hline Estudos & Ano & País \\
\hline Dias-Ribeiro et al. $^{4}$ & 2015 & Brasil \\
\hline Anic-Milosevic et $\mathrm{al}^{10}$ & 2010 & Croácia \\
\hline Fadeju et al. ${ }^{11}$ & 2013 & $\begin{array}{c}\text { Ghana, Nigéria e } \\
\text { Senegal }\end{array}$ \\
\hline Alcalde et al. ${ }^{12}$ & 2000 & Japão \\
\hline Hwang et $\mathrm{al}^{13}$ & 2002 & Coréia do Sul \\
\hline Scavone et al. ${ }^{14}$ & 2006 & Brasil \\
\hline Scavone et al. ${ }^{15}$ & 2008 & Brasil \\
\hline Al-Gunaid et al. ${ }^{16}$ & 2007 & Arábia Saudita \\
\hline Uysal et al. ${ }^{17}$ & 2009 & Turquia \\
\hline Gu et al. ${ }^{18}$ & 2011 & China \\
\hline Shindoi et al. ${ }^{19}$ & 2013 & Japão \\
\hline El Hayeck et al. ${ }^{20}$ & 2016 & Líbano \\
\hline Sinojyia et al. ${ }^{21}$ & 2014 & Índia \\
\hline Kalha et al. ${ }^{22}$ & 2008 & Índia \\
\hline Biradar e Madanagowda ${ }^{23}$ & 2010 & Índia \\
\hline Prabu et al. ${ }^{24}$ & 2012 & Índia \\
\hline Singh et al. ${ }^{25}$ & 2016 & Índia \\
\hline Sant'Ana et al. ${ }^{26}$ & 2009 & Brasil \\
\hline
\end{tabular}

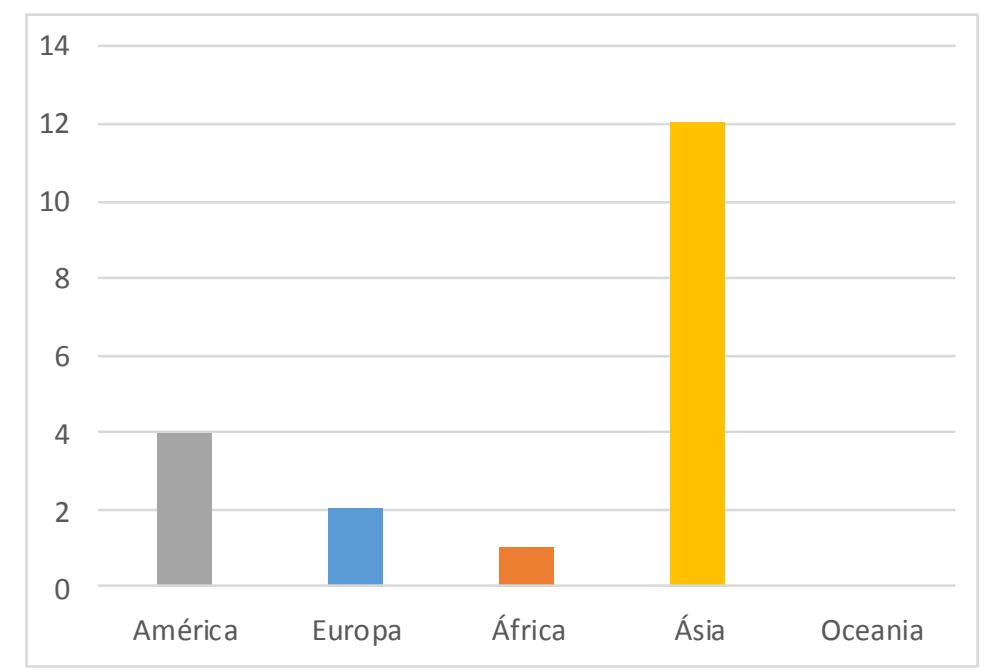

Gráfico 1: Distribuição dos estudos de acordo com os continentes sobre a técnica de análise cefalométrica dos tecidos moles proposta por Arnett et $\mathrm{al}^{9}$.

\section{CONCLUSÃO}

Por meio desse trabalho conclui-se que a técnica de análise cefalométrica dos tecidos moles proposta por Arnett et al. ${ }^{9}$ é conhecida e utilizada nas diversas partes do mundo. Além disso, a individualidade do paciente deve ser levada em consideração para planejar o tratamento, pois foi mostrado que indivíduos que supostamente apresentariam as mesmas características faciais, por serem de uma mesma raça, apresentam peculiaridades em seus padrões faciais devido a pertencerem a localidades geográficas diferentes. Foi possível notar também, que o gênero tem grande influência nessas características, pois pessoas de uma mesma raça e região, divergem significativamente quanto a características faciais, se pertencerem a gêneros distintos. 


\section{REFERÊNCIAS}

1. Goldsman S. The variation in skeletal and denture patterns in excellent adult facial types. Angle Orthod. 1959; 29(2):63-92.

2. Dierkes JM. The beauty of the face: an orthodontic perspective. J Am Dental Assoc. 1987; Spec:89E-95.

3. Peck H, Peck S. A concept of facial esthetics. Angle Orthod. 1970; 40(4):284-317.

4. Dias-Ribeiro E, Rocha JF,Sonoda CK, Song F,Beltrão RTS,Yaedú RYF,Sant'ana E. Comparative evaluation of facial profile normality standards in Braziliannortheast and in Brazilian-southeast female pacients. J Craniofa Surg. 2015; 26(7):2228-30.

5. Broadbent BH. A new x-ray technique and its application to orthodontia. Angle Orthod. 1931; $1(2): 45-66$

6. Hambeton RS. The orthodontic curtain. Angle Orthod. 1963; 33(4):294-8.

7. Arnett GW, Bergman RT. Facial keys to orthodontic diagnosis and treatment planning. Part I. Am J Orthod Dentofacial Orthop. 1993; 103(4):299-312.

8. Arnett GW, Bergman RT. Facial keys to orthodontic diagnosis and treatment planning. Part II. Am J Orthod Dentofacial Orthop. 1993; 103(4):395-411.

9. Arnett GW, Jelic JS, Kim J, Cummings DR, Beress A, Worley CM Jr et al. Soft tissue cephalometric analysis: diagnosis and treatment planning of dentofacial deformity. Am J Orthod Dentofacial Orthop. 1999; 116(3):239-53.

10. Anic-Milosevic S, Mestrovic S, Lapter-Varga M, Dumancic J, Slaj M. Analysis of the soft tissue profile in Croatians with normal occlusions and well-balanced faces. Eur J Orthod. 2011; 33(3):305-10.

11. Fadeju AD, Otuyemi OD, Ngom PI, Newman-Nartey M. A study of cephalometric soft tissue profile among adolescents from the three West African countries of Nigeria, Ghana and Senegal. J Orthod. 2013; 40(1):53-61.

12. Alcalde RE, Jinno T, Orsini G, Sasaki A, Sugiyama RM, Matsumura T. Soft tissue cephalometric norms in Japanese adults. Am J Orthod Dentofacial Orthop. 2000; 118(1):84-9.

13. Hwang HS, Kim WS, McNamara JA Jr. Ethnic Differences in the Soft Tissue Profile of Korean and European-American Adults with Normal Occlusions and Well-Balanced Faces. Angle Orthod. 2002; 72(1):72-80.

14. Scavone H Jr, Trevisan H Jr, Garib DG, Ferreira FV. Facial profile evaluation in Japanese-Brazilian adults with normal occlusions and well-balanced faces. Am J Orthod Dentofacial Orthop. 2006; 129(6):721-5.

15. Scavone H, Zahn-Silva W, Do Valle-Corotti KM, Nahás AC. Soft tissue profile in white Brazilian adults withnormal occlusions and well-balanced faces. Angle Orthod. 2008; 78(1):58-63

16. Al-Gunaid T, Yamada K, Yamaki M, Saito I. Softtissue cephalometric norms in Yemeni men. Am J Orthod Dentofacial Orthop. 2007; 132(5): 576.e7-14.

17. Uysal T, Yagci A, Basciftci FA, Sisman Y. Standards of soft tissue Arnett analysis for surgical planning in Turkish adults.Eur J Orthod. 2009; 31(4):449-56.

18. Gu Y, McNamara JA Jr, Sigler LM, Baccetti T. Comparison of craniofacial characteristics of typical Chinese and Caucasian young adults. Eur J Orthod. 2011; 33(2):205-11
19. Shindoi JM, Matsumoto Y, Sato Y, Ono T, Harada K. Soft tissue cephalometric norms for orthognatic and cosmetic surgery. J Oral Maxillofac Surg. 2013; 71(1):e24-30.

20. El Hayeck E, Bassil-Nassif N, Bouserhal J. Soft tissue norms: Conventional and based on true vertical in a Lebanese population. Int Orthod. 2016; 14(3):311-27.

21. Sinojiya J, Aileni KR, Rachala MR, Pyata JR, Mallikarjun V, Reddy M. Soft tissue esthetic norms for mahabubnagar population of southern India. J Clin Diagn Res. 2014; 8(1):255-9.

22. Kalha AS, Latif A, Govardhan SN. Soft-tissue cephalometric norms in a South Indian ethnic population. Am J Orthod Dentofacial Orthop. 2008; 133(6):876-81.

23. Biradar AK, Madanagowda SB. Establishment of South Indian soft tissue cephalometric norms using profile angles and esthetic analysis. World J Orthod. 2010; 11(4):e104-13.

24. Prabu NM, Kohila K, Sivaraj S, Prabu PS. Appraisal of the cephalometric norms for the upper and lower lips of the South Indian ethnic population. J Pharm Bioallied Sci. 2012; 4(Suppl 2):136-8.

25. Singh S, Deshmukh S, Merani V, Rejintal N. Mean values of Arnett's soft tissue analysis in Marata ethnic (Indian) population - a cephalometric studies. J Int Soc Prev Community Dent. 2016; 6(4):327-37.

26. Sant'ana E, Kuriki EU, Arnett W, Lautenschlager GA, Yaedu RY. Avaliação comparativa do padrão de normalidade do perfil facial em pacientes brasileiros leucodermas e em norte americanos. Rev Dent Press Ortodon Ortopedi Facial. 2009; 14(1):80-9.

\section{CONFLITO DE INTERESSES}

Os autores declaram não haver conflitos de interesse.

\section{AUTOR PARA CORRESPONDÊNCIA}

Marina Tavares Costa Nóbrega

marinatcn@hotmail.com

Submetido em 18/10/2017 Aceito em 07/12/2017 